of the most perplexing and aggravating of enterprises. And it must be confessed that Mr. Stevenson's work will do much to smooth the path of the unhappy individuals who cannot resist the temptation to meddle with bricks and mortar. It is also of interest for the information it gives as to architecture in relation to housebuilding, and from the excellent manner in which it treats of the principles of house-planning. It is a work to delight the eye, as well as to improve the mind, from the beautiful manner in which it is illustrated, and the goodness of its typography. The entire "getting-up" of the work, indeed, does honour to Messrs. Macmillan's press, and to the artists who have been engaged in its production. The greater part of the work is necessarily devoted to architectural details, but so much of it as is particularly given to the more strietly sanitary considerations of heating, water-supply, and drainage, is sound in principle. This is especially noteworthy, as it must be confessed that architects are too commonly deficient in knowledge on these important points-a knowledge on which the comfort and health of the inmates of a house are largely dependent. We commend this work most heartily to our readers, not only for the special knowledge it contains, but also for its general interest on a subject which appeals more or less to everyone.

The Therapeutics of Gynecology and Obstetrics. By W. B. A'Tkinson, M.A., M.D. London : Baillière, Tindall, \& Cox. -This work only calls for brief notice. It professes to give a summary of the methods now adopted in the treatment of the diseases of women. Its plan includes a synopsis of the diagnostic points of a disease, a description of the various methods used with a view to cure, and a résumé of the remedies employed. The synopsis of diagnostic points is short, and of no particular value. The descriptions of the methods of eure form the chief part of the work. These are given veually in the words of authors who have written upon the subject. Indeed, the work has been made up from the writings of authors whom the editor is pleased to cal "distinguished contemporary specialists." If the work will serve vo other purpose, it shows the unscientific, chaotic condition of the "therapentics of gynecology."

Transactions of the American Gynecological Society. Vol. IV. 1879.- This volume is quite up to the average of its predecessors. All the papers in it are contributed by American physicians, except one, which is by Mr. Spencer Wells. This is a case of removal of both ovaries for dysmeuorrhoea (Battey's operation), and illustrates well the difficulties of the operation, and the accidents that may befall a most experienced ovariotomist. Several questions of the greatest interest are discussed in the volume, of which intra-uterine medication, introduced by $\mathrm{Dr}$. White and Dr. Batley, and prolapse of the ovary, by Dr. Mundé, may be more especially mentioned. Dr. Reeves contributes a very interesting case of extra-uterine pregnancy, which was cured by the application of electricity. A paper by Dr. Van de Warker on "The Relation of Symptoms to Versions and Flexions of the Uterus" leaves the subject in as unsatisfactory a state as ever. The volume contains also an inter esting paper on Justo-minor Pelvis, by Dr. Lusk; one on Chrouic Inversion of the Uterus, by Dr. Byford, in which the author reverts to Dr. Tyler Smith's plan of restoring the inverted organ by means of pressure, exercised by an elastic bag introduced into the vagina. At the end of the volume is a valuable index to the works published on gynecological subjects during the previous year.

Messrs. W. J. ADAMs \& Co., of Fleet-street, have issued a sixpenny Improved District Railvay Map, which cannot but be found extremely useful to persons who have to travel much about the great city.

\section{ENTERIC FEVER IN TROPICAL CLIMATES.}

\section{To the Editor of THE LANCET.}

SIR,- - I am glad to observe that the question of "enteric" fever in India continues to obtain attention, and as I helieve, from the discussion which has already taken place on this subject, that the differences of opinion regarding the disease so called are really more as to its name than its reality, I propose, if you please, to briefly comment on the substance of a letter regarding it, which appeared in THE LAXCET of 3lst July, 1880.

What, then, is the precise sense in which the term "en. teric" is applied by the writer of that letter to the fever in India which he describes? If to a fever the result of endemic and climatorial influences acting upon particular diatheses, and individnal conditions, - the fever itself becoming in its course complicated with intestinal, that is, enteric ulceration,-there is no question that such a species of fever does occur among British soldiers in that country.

But inasmuch as the definition, arcording to wbich my inquiries were conducted, was " a sperific ferer with enteric ulceration, due to the presence of filth in air, earth or water," not one of the cases, the reports of which were brought before me, as a matter of fact came up to that definition.

In the same letter, reference is made to certain temperature standards as diagnostic of "enteric" from malarial fevers In my special reports from Madras, copies of which I had the honour to transmit to you, not only do the standards of temperature charts which I give in the first of these documents differ absolutely from each other, but the charts of individual cases given in my second report are in complete disaccord with each other, as they are with the standard given in your correspondent's letter. And so, with the other phenomena of individual cases given in my reports, they are in disaceord with those recorded in the same communication.

Your correspondent alludes to " post-wortem appearances pathognomonic of enteric fever." So far as the extracts from authorities and writers given in my reports justify a conclusion, that conclusion is that in fatal cases of ferer due to pythogenic causes, there are no post-mortem appearances of a nature beyond such as exist in fatal cases of non-specific fevers due to endemic and climatorial causes in India; also, that appearances undistinguishable from them occur in other diseases than fever, and as results of certain poisons.

Your correspondent admits that it is hard to obtain positive evidence as to the pythogenic nature of enteric fever in India. With reference to the cases recoried in my reports, I remark again, that, by the showing of individual medical officers, no such evidence was actually demonstrated, although often assumed, to the relative omis-ion of due consideration, I fear, of such general conditions of climate, season, and "endemic" influences as were actually the cause.

As I have observed in my reports, the circumstance that the relative mortality by fever in India has of late years increased, and that too since the more ceneral spread of the pythogenic theory as against the clim toricul, indicates that the time has fully arrived for a reconsideration of the subject with reference, at least, to British troous in that country.

$$
\text { Yours faithfully, }
$$

Cambridge Gardens, w. C. A. GORDON, Surgcon-General,

The "City Press" records the presentation of a testimonial to the senior medical officer of the City of London Infirmary, consisting of an elegant silver salver, which bore the following inscription: "Presented to Charles Hope Buncombe, F.R.C.S., by the officers and assistants of the in. firmary of the City of London Union. August, 1880." The address bore the signatures of the whole staff." The following is the inscription: "To Charles Hope Buncombe, Eso., F.R.C.S. - We, the undersigned officers and assistants of the Infirmary of the City of London Union, beg to offer you our sincere congratulations on the dismissal of the untounded charge of manslaughter brought against you; and as a slight memento of our sympathy for the anviety and annoyance you have passed through, we ask your acceptance of a silver salver, with our best wishes for your future health and happiness." 